\title{
Spectrophotometric Determination of Cobalt(II) in Water after Preconcentration by Sorption of Its Nitroso R Complex with Poly(chlorotrifluoroethylene) Resin $\dagger$
}

\author{
Liping Zhang and Kikuo Terada ${ }^{\dagger}$ \\ Department of Chemistry, Faculty of Science, Kanazawa University, \\ Kakuma, Kanazawa 920-11, Japan
}

\begin{abstract}
A simple and rapid method has been established for spectrophotometric determination of cobalt(II) in water after preconcentration by sorbing the nitroso $\mathrm{R}$ (sodium-1-nitroso-2-hydroxynaphthalene-3,6-disulfonate) complex of cobalt(II) on poly(chlorotrifluoroethylene) resin. The cobalt-nitroso $R$ complex was quantitatively retained on the resin as an ion associate complex with tetrabutylammonium cation in the range of $\mathrm{pH} 5.5$ to 8.5. The retention capacity was $41.6 \mu \mathrm{g}(0.71 \mu \mathrm{mol}) \mathrm{Cog}^{-1}$ resin at a maximum flow rate of $30 \mathrm{ml} \mathrm{min}^{-1}$. Cobalt retained on the resin column was completely extracted with $5 \mathrm{ml}$ of methanol which was submitted to spectrophotometric measurement at $550 \mathrm{~nm}$ after $1 \mathrm{ml}$ of $1.0 \mathrm{~mol} \mathrm{dm}^{-3}$ nitric acid was added. The proposed method was applied to a river water sample.
\end{abstract}

Keywords Cobalt, preconcentration, nitroso-R salt, poly(chlorotrifluoroethylene) resin, spectrophotometry

In spite of recent advances in instrumental analysis, a direct determination of trace elements in complex matrices, such as environmental, biological, mineral, ore and high purity materials, seems still to be difficult because of insufficient sensitivity and selectivity of the methods. Thus, enrichment and separation of the analytes is important for the determination of cobalt, because of its extremely low concentration in natural water. Among a wide variety of methods proposed and used for preconcentration of cobalt, solvent extraction and column extraction using various sorbents have been most frequently used. The latter is superior to the former in its ability to treat a large volume of samples in a closed system free from contamination, with a high concentration factor.

The following three types of sorbents have been employed for concentration of trace metals including cobalt: (i) ligand-immobilized sorbents ${ }^{1-3}$, (ii) ligandimpregnated sorbents ${ }^{4-7}$, and (iii) unloaded sorbents which collect the metal complex previously formed in an aqueous solution. ${ }^{8-12}$ In the case of type (iii), Amberlite $\mathrm{XAD}$ resins have been used as column packings, combined with various kinds of ligands. On the other hand, the present authors have found that poly(chlorotrifluoroethylene) resin (PCTFE) effectively adsorbs some metal complexes. The metal retained on the polymer can be easily eluted with hydrochloric acid or methanol. ${ }^{13,14}$

$\dagger$ Presented at the ASIANALYSIS II, August 9-13, 1993, Changchun, China.

It To whom correspondence should be addressed.

K. T. Present address: 3-10-7, Nomachi, Kanazawa 921, Japan.
This polymer has some advantages over XAD resins: (i) excellent chemical and mechanical resistance making it possible to be used repeatedly, and (ii) no swelling in any solvent, which allows a high flow rate of the sample passage to be attained. Recently, this method has been satisfactorily applied to analysis of 8-quinolinol- $\mathrm{Cu}$ (fungicide) in the environmental water. ${ }^{15}$

A highly specific reagent for cobalt complexation, nitroso $R$ salt which gives a water-soluble red complex, provides a very sensitive and selective method for the determination of traces of cobalt. ${ }^{16}$ However, the detection limit obtained by the direct spectrophotometric measurements using $1.0 \mathrm{~cm}$ cell was about $50 \mu \mathrm{g} \mathrm{dm}^{-3}$, which is about 20 times that obtained with ICP-AES but not low enough for determining cobalt(II) in natural waters. Therefore, in the present study, a technique to preconcentrate cobalt by adsorbing its nitroso $\mathbf{R}$ complex onto PCTFE resin, was investigated in order to establish a simple and rapid method for spectrophotometric determination of cobalt in natural water.

\section{Experimental}

\section{Apparatus}

A Shimadzu Model UV-160 UV/VIS spectrophotometer with a $1.0 \mathrm{~cm}$ quartz cell was used for absorbance measurement. A small volume flow cell $(\phi 5 \mathrm{~mm})$ mounted in a Nihonbunko Model U-best UV spectrophotometer and a Tokyo Rikakikai Model MP-3 peristaltic pump were used in the flow system for column experiments.

The column was a glass tube $(10 \mathrm{~mm}$ i.d. $)$ with a coarse sintered glass disc and a stop cock at the bottom. 


\section{Reagents}

All chemicals and solvents used were of analytical reagent or poisonous metal analysis grade. Methanol was a Nacalai Tesque brand high purity solvent.

Deionized distilled water (DDW) prepared with a Barnstead Nanapure system was used in all experiments.

A commercially available PCTFE (Neoflon, Daikin Kogyo, Osaka, molding powder) was sieved to $80-100$ mesh and finer than 100 mesh sizes. Specific surface areas of the powders were measurured by BET method and found to be $3.27 \mathrm{~m}^{2} \mathrm{~g}^{-1}$ for the latter. Those powders were purified by washing with a mixture of hydrochloric acid and methanol $(1: 1 \mathrm{v} / \mathrm{v})$, and then washed with DDW and stored in methanol prior to use.

A $1000 \mathrm{mg} \mathrm{dm}^{-3}$ cobalt(II) stock solution was prepared by dissolving cobalt(II) nitrate reagent in $0.1 \mathrm{~mol} \mathrm{dm}^{-3}$ hydrochloric acid.

A $0.2 \%$ nitroso $\mathrm{R}$ salt solution and a tetrabutylammonium chloride (TBAC) solution were prepared by dissolving each reagent in DDW. A citrate buffer solution was prepared by dissolving $21 \mathrm{~g}$ of citric acid and $11.8 \mathrm{~g}$ sodium hydroxide in $100 \mathrm{ml}$ of DDW.

\section{Preparation of PCTFE column}

PCTFE powder was slurried with methanol by using an ultrasonic vibrator for $5 \mathrm{~min}$ (under the condition $1.0 \mathrm{~g}$ of $100 \mathrm{mesh}$ resin became $2.2 \mathrm{ml}$ ), and then poured into the glass column. After the methanol level was brought to the column bed, the column was carefully washed with at least $50 \mathrm{ml}$ of DDW without disturbing the resin bed. The prepared column was always filled with DDW in order to prevent the resin bed from drying.

\section{General procedure}

To an aliquot of $\mathrm{Co}^{\mathrm{II}}$ solution were added $1 \mathrm{ml}$ of citrate buffer solution, $2 \mathrm{ml}$ of $0.2 \%$ nitroso $\mathrm{R}$ salt solution and $1 \mathrm{ml}$ of TBAC solution as a counter ion reagent. The resulting solution ( $c a . \mathrm{pH} 6.5$ ) was passed through the PCTFE column at a given flow rate with the aid of a peristaltic pump. The cobalt retained on the column was eluted with $5 \mathrm{ml}$ of methanol. After $1 \mathrm{ml}$ of $1.0 \mathrm{~mol} \mathrm{dm}^{-3}$ nitric acid was added, the absorbance of the effluent was measured by a spectrophotometer at $550 \mathrm{~nm}$. The PCTFE column can be used repeatedly after washing with DDW.

The chromatographic characteristics of Co-nitroso $\mathbf{R}$ complex on PCTFE column were examined using a flow system. An aqueous complex solution containing TBAC and with $\mathrm{pH}$ adjusted to $c a .6 .5$ was passed through the PCTFE column connected to the system using a peristaltic pump. The absorbance of the effluent was continuously measured using a small volume flow cell.

\section{Results and Discussion}

Effect of $\mathrm{pH}$ on the retention of Co-nitroso $\mathrm{R}$ complex The recovery of Co-nitroso $R$ complex from an aqueous solution was examined in the range of $\mathrm{pH} 3.0$ to 11. A $100 \mathrm{ml}$ portion of the complex solution (Co: $10 \mu \mathrm{g} \mathrm{dm}^{-3}$ ) was passed through the column. The results are shown in Fig. 1 . The quantitative recovery of cobalt is attained in the range of $\mathrm{pH} 5.5$ to 8.5. This fact indicates that change in the $\mathrm{pH}$ of natural water is not a significant factor which would affect the recovery of the Co complex. The optimum $\mathrm{pH}$ of the solution was selected to be around 6.5 in all experiments.

\section{Retention and elution of Co-nitroso $R$ complex}

The loading curves for different concentrations of Conitroso $\mathrm{R}$ complexes are shown in Fig. 2. An increase in

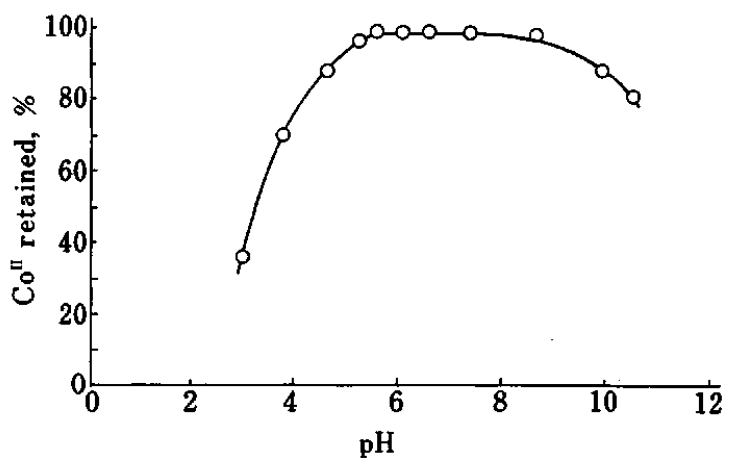

Fig. 1 Effect of $\mathrm{pH}$ on retention of cobalt-nitroso $\mathrm{R}$ complex.

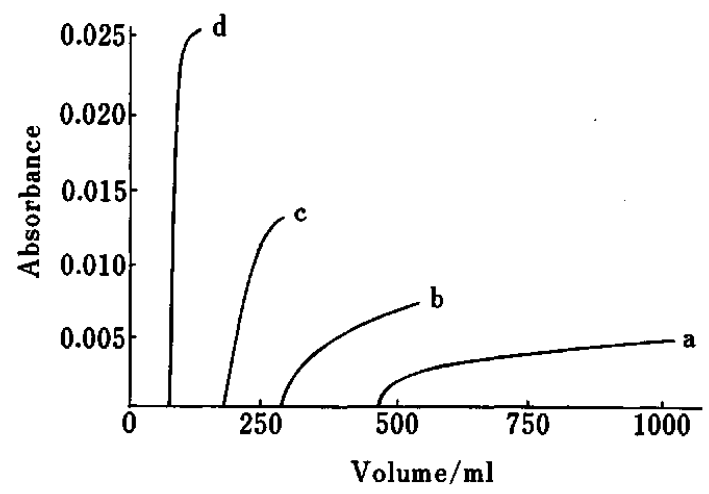

Fig. 2 Loading curves of cobalt-nitroso $\mathrm{R}$ complex for different cobalt concentrations: (a) 0.025 , (b) 0.05 , (c) 0.1 and (d) $0.25 \mathrm{mg} \mathrm{dm}^{-3}$.

Table 1 Retention capacity of PCTFE resin for cobaltnitroso $R$ complex as a function of cobalt(II) concentration

\begin{tabular}{|c|c|c|}
\hline $\begin{array}{c}\mathrm{Co}^{\text {II }} \text { concentration/ } \\
\mathrm{mg} \mathrm{dm}^{-3}\end{array}$ & \multicolumn{2}{|c|}{$\begin{array}{c}\text { Retention capacity } \\
\mu \mathrm{g} \mathrm{g}^{-1}\left(\mu \mathrm{mol} \mathrm{g}^{-1}\right)\end{array}$} \\
\hline 0.025 & 38.6 & $(0.66)$ \\
\hline 0.05 & 39.2 & $(0.67)$ \\
\hline 0.10 & 43.0 & $(0.73)$ \\
\hline 0.25 & 45.4 & $(0.77)$ \\
\hline Average & 41.6 & $(0.71)$ \\
\hline
\end{tabular}

a. $0.5 \mathrm{~g}$ of PCTFE was used. 
retention was observed with increase in $\mathrm{Co}^{\text {II }}$ concentration. The sorption capacity of Co-nitroso $R$ complex by PCTFE resin for different concentrations of $\mathrm{Co}^{\mathrm{II}}$ are listed in Table 1 . The average retention capacity was calculated to be $41.6 \mu \mathrm{g}(0.71 \mu \mathrm{mol}) \mathrm{g}^{-1}$ polymer. This relatively low capacity may be attributed to the small surface area of PCTFE resin $\left(3.27 \mathrm{~m}^{2} \mathrm{~g}^{-1}\right)$, but it is considered to be enough for the preconcentration of trace cobalt(II) in natural water. Moreover, the small surface area of the resin also minimizes the volume of eluent used, so that a higher concentration factor might be attained. Table 2 shows the retention capacity for Co-nitroso $\mathrm{R}$ complex (Co: $0.1 \mathrm{mg} \mathrm{dm}^{-3}$ ) from the aqueous solution of different ionic strength. As can be seen from the table, with an increase in ionic strength of the aqueous solution the retention capacity decreases.

A complete elution of the complex from the PCTFE column was attained by passing $3 \mathrm{ml}$ of methanol; however, $5 \mathrm{ml}$ methanol was used to fill a $1.0 \mathrm{~cm}$ cell with the eluate.

\section{Effect of nitroso $R$ salt concentreation}

For an analytical method using nitroso $R$ salt as a colorimetric reagent for cobalt, it is important to determine the concentration of the reagent to be used. Although, an excess of the reagent used would assure a complete complexation of cobalt in an aqueous solution, a high concentration of the reagent might cause a blank problem for the samples with very low $\mathrm{Co}^{\text {II }}$ concentration.

Table 2 Retention capacity of PCTFE resin for cobaltnitroso $\mathrm{R}$ complex from solutions of different matrices

\begin{tabular}{cc}
\hline Matrix $^{\mathrm{a}}$ & Retention capacity $^{\mathrm{b}} / \mu_{\mathrm{g} \mathrm{g}} \mathbf{g}^{-1}$ \\
\hline $\mathrm{DDW}$ & 43.0 \\
$1.4 \% \mathrm{NaCl}$ & 40.1 \\
$3.5 \% \mathrm{NaCl}$ & 36.5 \\
\hline
\end{tabular}

a. Citrate buffer was added (pH 6.5).

b. $0.5 \mathrm{~g}$ of PCTFE resin was used.

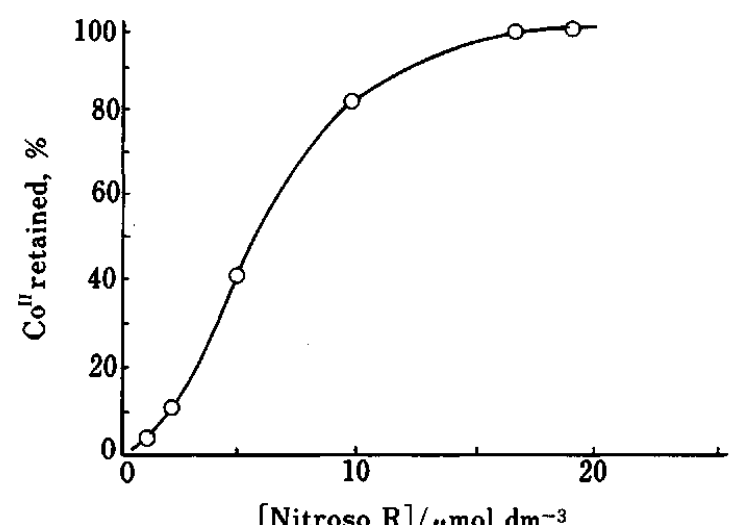

Fig. 3 Effect of nitroso R salt concentration on retention of cobalt-nitroso $R$ complex.
The recovery of cobalt complex was examined as a function of concentration of nitroso $R$ reagent using $20 \mu \mathrm{g} \mathrm{dm}^{-3} \mathrm{Co}^{\text {II }}$ solution at $\mathrm{pH}$ 6.5. The results shown in Fig. 3 indicate that the recovery of cobalt is highly dependent on the reagent concentration. The retention recovery steeply increased from 1 to $10 \mu \mathrm{mol} \mathrm{dm}^{-3}$ in the reagent concentration, then gradually increased to reach quantitative retention at the concentration of $16 \mu \mathrm{mol} \mathrm{dm}^{-3}$. Thus, the reagent concentration of $16 \mu \mathrm{mol} \mathrm{dm}^{-3}$, i.e. about 50 times that of cobalt(II), was selected because it gave a reasonably high recovery of cobalt.

\section{Effect of ion association reagent}

Because nitroso $R$ salt forms an water-soluble negatively charged complex with cobalt(II) ion, which shows strong polarity, cobalt was not adsorbed on nonpolar PCTFE resin. However, by the addition of an ion association reagent such as TBAC, the complex anion was quantitatively retained on the polymer. This fact indicates that the formation of an ion associate between Co-nitroso $\mathrm{R}$ complex anion and $\mathrm{TBA}^{+}$cation gives a less polar bulky complex leading to an increase in retention ability of cobalt on the PCTFE column.

The effect of TBAC concentration on retention of the complex was investigated with $100 \mathrm{ml}$ of $20 \mathrm{\mu g} \mathrm{dm}^{-3} \mathrm{Co}-$ nitroso $\mathrm{R}$ complex solution at $\mathrm{pH}$ 6.5. The results are shown in Fig. 4. A quantitative retention of cobalt(II) was attained at a TBAC concentration above $9 \mu \mathrm{mol}$ $\mathrm{dm}^{-3}$. The adsorption of the cobalt complex with TBAC on PCTFE column is described by the following equation:

$$
\begin{aligned}
& \text { Co-NRS }+n \mathrm{TBA}^{+}=\mathrm{Co}-\mathrm{NRS}\left(\mathrm{TBA}^{+}\right)_{n(\mathrm{aq})} \\
& K=\frac{\left[\mathrm{Co}-\mathrm{NRS}\left(\mathrm{TBA}^{+}\right)_{n}\right]_{(\mathrm{aq})}}{[\mathrm{Co}-\mathrm{NRS}]\left[\mathrm{TBA}^{+}\right]^{n}} \\
& \text { Co-NRS }\left(\mathrm{TBA}^{+}\right)_{n(\mathrm{aq})}=\mathrm{Co}-\mathrm{NRS}\left(\mathrm{TBA}^{+}\right)_{n(\mathrm{resin})} \\
& K_{\mathrm{D}}=\frac{\left[\mathrm{Co}-\mathrm{NRS}\left(\mathrm{TBA}^{+}\right)_{n}\right]_{(\mathrm{resin})}}{\left[\mathrm{Co}-\mathrm{NRS}\left(\mathrm{TBA}^{+}\right)_{n}\right]_{(\mathrm{aq})}}
\end{aligned}
$$

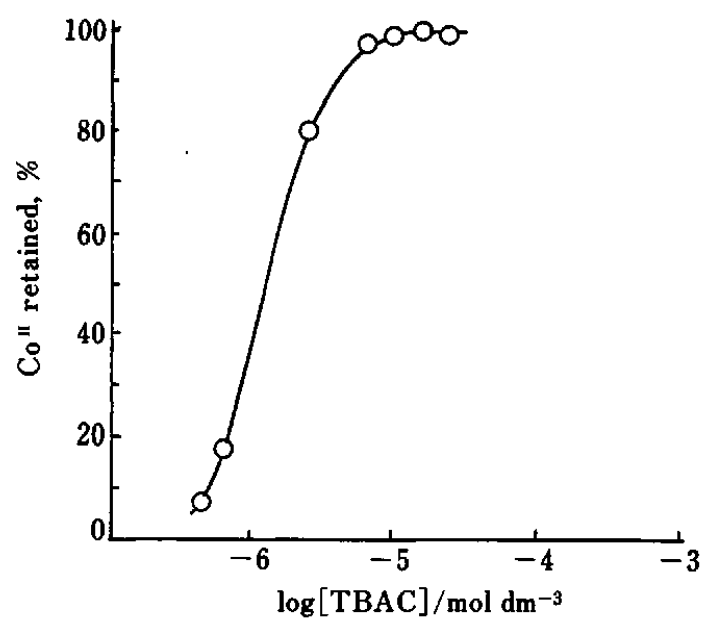

Fig. 4 Effect of tetrabutylammonium chloride concentration on retention of cobalt-nitroso $R$ complex. 


$$
D=\frac{\Sigma C_{\text {resin }}}{\Sigma C_{\text {aq }}}=\frac{\left[\mathrm{Co}-\mathrm{NRS}\left(\mathrm{TBA}^{+}\right)_{n}\right]_{\text {(resin) }}}{[\mathrm{Co}-\mathrm{NRS}]_{(\mathrm{aq})}}
$$

where $\Sigma C_{\text {aq }}$ and $\Sigma C_{\text {resin }}$ are the total concentration of cobalt in aqueous phase and PCTFE resin phase, respectively, NRS represents nitroso R salt, and $D$ is a distribution coefficient for the ion associate complex.

If we combine Eqs. (1) and (2) into Eq. (3), the distribution coefficient $D$ can be expressed by the following equation:

$$
\begin{aligned}
& \quad D=K \cdot K_{D}\left(\mathrm{TBA}^{+}\right)^{n} \\
& \text { or } \log D=\log K+\log K_{D}+n \log \left(\mathrm{TBA}^{+}\right)
\end{aligned}
$$

Therefore, according to Eq. $5, \log D$ should increase linearly with the concentration of $\mathrm{TBA}^{+}$with a slope of $n$. The value of $n$ was determined from the slope of the log $D$ vs. $\log \left(\mathrm{TBA}^{+}\right)$plot shown in Fig. 5 and found to be 2 . This fact indicates that a molecule of Co-nitroso $R$ complex is associated with $\mathrm{TBA}^{+}$in the ratio of $1: 2$. Since the produced bulky complex may become more hydrophobic than the Co-nitroso $R$ complex, the adsorbability on the hydrophobic polymer is significantly increased. Since the Co-nitroso $R$ complex is regarded to be charged -3 , the value of $n$ would be expected to be 3 to form a neutral complex. However, in the case of $\mathrm{Cu}^{\mathrm{II}}$-8-quinolinol-5-sulfonate complex, $\left[\mathrm{Cu}^{\mathrm{II}}-\mathrm{SO}_{x}\right]^{2-}$, it was found that the complex was associated with $\mathrm{TBA}^{+}$in the ratio of $1: 1$ and was quantitatively retained on PCTFE resin. Moreover, tetraphenylporphine tetrasulfonate and humic acid were also effectively adsorbed on the polymer from sodium acetate/acetic acid buffer solution. In these cases, the sodium ion seemed to be the counter ion which associates to the above-mentioned bulky anions. In the present study the sodium ion also would associate with the Conitroso R-TBA complex anion, and the ion-associate complex was adsorbed on the resin.

\section{Effect of flow rate on retention of cobalt(II)}

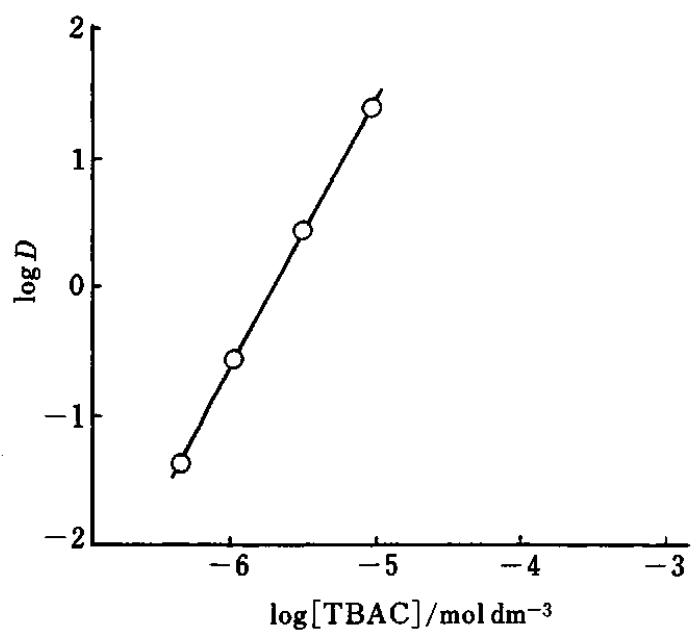

Fig. 5 Relationship between $\log D$ and $\log$ [TBAC].
The effect of flow rate on recovery of cobalt(II) was examined by passing $100 \mathrm{ml}$ of $20 \mu \mathrm{g} \mathrm{dm}^{-3} \mathrm{Co}$-nitroso $\mathrm{R}$ complex solution through the PCTFE column at pH 6.5. A quantitative and reproducible retention of the complex was attained at flow rates between 6 and $30 \mathrm{ml} \mathrm{min}^{-1}$.

Effect of the volume of sample solution on retention of cobalt(II)

The recovery of cobalt(II) was examined using different volumes of sample solution ranging from 100 to $1000 \mathrm{ml}$. The results shown in Table 3 indicate that there is little change in recoveries of the element over the volume range described above. In the present study, since only $5 \mathrm{ml}$ of an eluent is enough to completely extract cobalt from the PCTFE column, high concentration factor could be easily achieved by using a larger volume of a sample in the case of low concentraion cobalt.

\section{Selection of wavelength for measuring absorbance}

The wavelength of maximum absorbance of the Conitroso R complex was found to be $415 \mathrm{~nm}$, as shown in Fig. 6-a. However, the absorbance by the reagent itself was also very high at this wavelength (Fig. 6-b). Therefore, in this study, the absorbance of cobalt complex was measured at wavelength $550 \mathrm{~nm}$, at which the absorbance of the reagent is negligibly low. The absorbance difference between the complex and the reagent is nearly equal to that measured at wavelength $415 \mathrm{~nm}$.

\section{Effect of foreign ions and removal of interference}

Interferences with the spectrophotometric determina-

Table 3 Effect of sample volume on the recovery of cobalt

\begin{tabular}{ccc}
\hline $\begin{array}{c}\text { Sample volume/ } \\
\mathrm{ml}\end{array}$ & $\begin{array}{c}\mathrm{Co}^{\mathrm{II}} \text { concentration/ } \\
\mu \mathrm{g} \mathrm{dm}^{-3}\end{array}$ & Recovery $^{\mathrm{a}} \%$ \\
\hline 100 & 10 & 94.3 \\
250 & 10 & 96.2 \\
500 & 10 & 98.3 \\
1000 & 5 & 97.6 \\
\hline
\end{tabular}

a. Average of three runs.

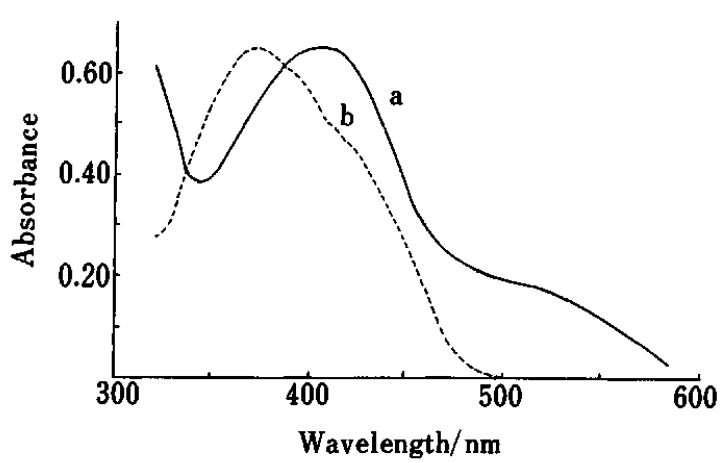

Fig. 6 Absorption spectra of (a) cobalt-nitroso $\mathbf{R}$ complex and (b) nitroso $R$ salt in methanol. 
Table 4 Interference of foreign ions

\begin{tabular}{lccc}
\hline Ion & $\begin{array}{c}\text { Concentration/ } \\
\mathrm{mg} \mathrm{dm}^{-3}\end{array}$ & Absorbance & Absorbance $^{\mathrm{b}}$ \\
\hline $\mathrm{Co}^{\mathrm{II}}$ & 0.05 & 0.042 & 0.042 \\
$\mathrm{Fe}^{\mathrm{III}}$ & 5.0 & 0.194 & 0.002 \\
$\mathrm{Cu}^{\mathrm{II}}$ & 0.5 & 0.059 & 0.002 \\
$\mathrm{Cr}^{\mathrm{VI}}$ & 0.1 & 0.001 & - \\
$\mathrm{Ni}^{\mathrm{II}}$ & 1.0 & 0.002 & - \\
$\mathrm{Mn}^{\mathrm{II}}$ & 1.0 & 0.002 & - \\
$\mathrm{Vo}_{2}{ }^{+}$ & 1.0 & 0.002 & - \\
\hline
\end{tabular}

a. Methanol effluent.

b. Methanol effluent added $1.0 \mathrm{ml}$ of $1.0 \mathrm{~mol} \mathrm{dm}^{-3} \mathrm{HNO}$.

Table 5 Analysis of rive-water for cobalt(II) ${ }^{\mathrm{a}}$

\begin{tabular}{cccc}
\hline \multirow{2}{*}{ Sample volume $/ \mathrm{ml}$} & \multicolumn{2}{c}{$\mathrm{Co}^{\mathrm{II}} / \mu \mathrm{g} \mathrm{dm}^{-3}$} & \\
\cline { 2 - 3 } & added & found & \\
\hline 250 & - & $1.5_{2}$ & - \\
& 1.0 & $2.4_{6}$ & $94 \pm 5$ \\
\multirow{2}{*}{500} & 5.0 & $6.3_{2}$ & $96 \pm 7$ \\
& - & $1.4_{8}$ & - \\
& 2.5 & $3.9_{3}$ & $98 \pm 6$ \\
& 5.0 & $6.1_{3}$ & $93 \pm 5$ \\
\hline
\end{tabular}

a. Average of three runs.

tion of cobalt(II) as its nitroso $\mathrm{R}$ complex had been reported for $\mathrm{Fe}^{\mathrm{III}}, \mathrm{Cu}, \mathrm{Cr}^{\mathrm{IV}}, \mathrm{Ni}, \mathrm{VO}_{3}{ }^{+}$, and $\mathrm{Mn}^{\mathrm{II}} .{ }^{17}$ However, interferences with $\mathrm{Cr}^{\mathrm{IV}}, \mathrm{Mn}^{\mathrm{II}}$ and $\mathrm{VO}_{3}{ }^{+}$were negligible in concentrations of 2, 20 and 20 times that of cobalt. The interferences by the other ions which may form their complexes with the reagent could be minimized by adding $1 \mathrm{ml}$ of $1.0 \mathrm{~mol} \mathrm{dm}^{-3}$ nitric acid to the methanol effluent prior to absorbance measurement. By this treatment, the complexes of these metals might dissociate. The results summarized in Table 4 indicate that interferences by $\mathrm{Fe}^{\mathrm{III}}$ and $\mathrm{Cu}$ become negligibly small up to concentrations 100 and 10 times that of cobalt, respectively. Then, the proposed method can be regarded as highly selective and sensitive for determination of cobalt.

\section{Analysis of river water for cobalt(II)}

To confirm the usefulness of the proposed method, concentration of cobalt(II) in a sample of river water (Tatsumi canal flowed from Sai-river, Kanazawa City) was measured. Replicate results for $250 \mathrm{ml}$ and $500 \mathrm{ml}$ of the water samples are given in Table 5. The satisfactory results of recovery were obtained and the average concentration of cobalt(II) was $1.5 \pm 0.2 \mu \mathrm{g} \mathrm{dm}^{-3}$.

The authors are acknowledge their thanks to Mr. M. Miyamoto, Industrial Research Institute of Ishikawa for his kind help in measurements of the specific surface area of PCTFE resin. This work was partially supported by Grant-inAid for General Scientific Research No. 03453041, from the Ministry of Education, Science and Culture of Japan.

\section{References}

1. R. E. Sturgeon, S. S. Berman, S. N. Willie and J. A. H. Desaurniers, Anal. Chem., 53, 2337 (1981).

2. M. A. Marshall and H. A. Mottola, Anal. Chem., 55, 2089 (1983).

3. S. K. Sahni and J. Reedijik, J. Coord. Chem. Rev., 59, 1 (1984).

4. K. Terada and K. Nakamura, Talanta, 28, 123 (1981).

5. R. Stella, M. T. G. Valentini and L. Maggi, Anal. Chem., 57, 1941 (1985).

6. C. Samara and Th. A. Kouimtzis, Anal. Chim. Acta, 174, 305 (1985).

7. A. Tong, Y. Akama and S. Tanaka, Anal. Chim. Acta, 230, 175 (1990).

8. S. Taguchi and K. Goto, Talanta, 27, 819 (1980).

9. R. E. Sturgeon, S. S. Berman and S. N. Willie, Talanta, 29, 167 (1982).

10. J. N. King and J. S. Fritz, Anal. Chem., 57, 1016 (1985).

11. Y. Sakai and N. Mori, Talanta, 33, 161 (1986).

12. K. Isshiki and E. Nakayama, Anal. Chem., 59, 291 (1987).

13. C. Akita, K. Matsumoto and K. Terada, Anal. Sci., 3, 473 (1987).

14. T. Yamaguchi, Z. Liping, K. Matsumoto and K. Terada, Anal. Sci., 8, 851 (1992).

15. N. Yamada, B. Tomita, K. Chaya and N. Murakami, Eisei Kagaku, 38, 188 (1992).

16. B. D. Guerin, Analyst [London], 81, 409 (1956).

17. M. Suzuki and T. Takeuchi, Bunseki Kagaku, 9, 179 (1960).

(Received November 2, 1993) (Accepted November 24, 1993) 